\title{
Matrix proteoglycans as effector molecules for epithelial cell function
}

\author{
C.W. Frevert* and P.L. Sannes ${ }^{\#}$
}

\begin{abstract}
Matrix proteoglycans are complex molecules composed of a core protein and glycosaminoglycan side chains. Once thought to be the molecular glue providing structural support and imparting biomechanical properties to lung tissue, it is now apparent that proteoglycans are important biological modifiers which regulate processes such as lung development, homeostasis, inflammation and wound healing. The diverse roles of proteoglycans in the extracellular matrix suggest that these molecules play a critical role in normal and diseased lungs. This short article will discuss the role extracellular matrix proteoglycans play in regulating epithelial cell function in the lungs.
\end{abstract}

KEYWORDS: Chondrotin sulphate, epithelial cell, heparan sulphate, perlecan, proteoglycans, versican

$\mathbf{T}$ he primary function of the lungs is to allow for the diffusion of oxygen and carbon dioxide into and out of the blood. Therefore, the preservation of normal lung function is critical. The alveolar epithelium plays an important role in maintaining lung function through a number of different processes including production of surfactant and surfactant proteins [1], pulmonary host defences [2-5] and the formation of a tight barrier which keeps the airspaces dry through the active transport of sodium and chloride and the passive movement of water [6, 7]. Because of the importance of the pulmonary epithelium in maintaining normal lung function, it is critical to understand the mechanisms responsible for maintaining epithelial integrity. Recent evidence suggests that extracellular matrix plays an important role in regulating epithelial cell function. The extracellular matrix is found at the basal surface of epithelial cells in the lungs (fig. 1). It is composed of a number of components, including laminin, collagens, fibronectin, tenascin and proteoglycans. These extracellular matrix molecules are required for the development of a highly organised three-dimensional microarchitecture that provides structural support for epithelial cells. For many years it was considered that the primary role of extracellular matrix was its structural and biomechanical properties. It is now known to have many physiological and pathophysiological roles through the regulation of cellular processes such as migration, adhesion, proliferation, apoptosis and differentiation. An important element of the lung's extracellular matrix is a group of molecules called proteoglycans. The goal of this article is to discuss the role of extracellular matrix proteoglycans in regulating epithelial cell function in normal and diseased lungs.

\section{PROTEOGLYCANS IN NORMAL LUNGS Proteoglycans}

Proteoglycans are a family of charged molecules that contain a core protein and one or more covalently attached glycosaminoglycan side chain. The complexity and diversity of proteoglycans are derived from $\sim 30$ different core proteins of varying size and structure (10$500 \mathrm{kDa})$, and the considerable variability in the number $(1->100)$ and types of glycosaminoglycan side chains attached [8]. Proteoglycans are found in the extracellular matrix, the plasma membrane of cells and in intracellular structures.

\section{Extracellular matrix proteoglycan families}

There are three families of extracellular matrix proteoglycans, which include the large aggregating chondroitin sulphate proteoglycans (lecticans), the small leucine-rich chondroitin sulphate proteoglycans, and the heparan sulphate proteoglycans [8-11]. Lecticans include aggrecan, neurocan, brevican and versican. This family of proteoglycans has an N-terminal globular domain that contains a hyaluronan binding site and a C-terminal globular domain. The central domains of these proteoglycans are of variable length and contain multiple sites for the addition of chondroitin sulphate and dermatan sulphate. Versican, a chondroitin sulphate proteoglycan found in the extracellular matrix of the lungs, has four isoforms, V0, V1, V2 and V3,
AFFILIATIONS

*Pulmonary and Molecular Pathology Research Laboratories at the Seattle, Dept of Veterans Affairs Medical Center, and the Division of Pulmonary/Critical Care Medicine, Dept of Medicine, University of Washington School of Medicine, Seattle, WA, and

${ }^{\#}$ Dept of Molecular Biomedical Sciences, College of Veterinary Medicine, North Carolina State University, Raleigh, NC, USA.

CORRESPONDENCE

C.W. Frevert

Seattle VAMC Pulmonary Research Group

Seattle VA Medical Center $151 \mathrm{~L}$

1660 S. Columbian Way

Seattle

WA 98108

USA

Fax: 12067685289

E-mail: cfrevert@u.washington.edu

\section{SUPPORT STATEMENT}

VA Medical Research (C.W. Frevert), NIH HL4497 (P.L. Sannes), and the State of North Carolina HL-24748 (P.L. Sannes). 


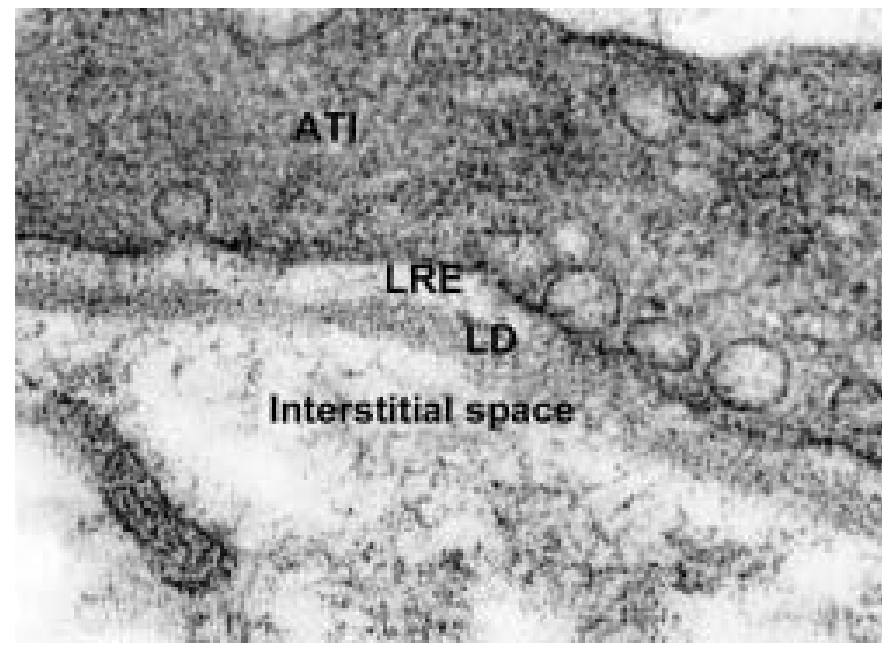

FIGURE 1. Ultrastructure of the extracellular matrix of a type I epithelial cell (ATI). Adjacent to the epithelial cell is the basement membrane with the lamina rara externa (LRE) and the lamina densa (LD), as seen in routinely prepared tissues by electron microscopy.

which carry varying amounts of chondroitin sulphate side chains [11]. The mRNA for versican isoforms V0, V1 and V3, but not V2, are found in normal lungs [12]. Small leucine-rich proteoglycans are extracellular molecules that bind to transforming growth factor (TGF)- $\beta$, surfactant protein $D$, collagens and other extracellular matrix molecules [11, 13, 14]. The small leucine-rich chondroitin sulphate proteoglycans have relatively small core proteins $(30-50 \mathrm{kDa})$ and examples in the lungs include decorin, biglycan and lumican.

The core proteins of decorin and biglycan are highly homologous, but the core protein of decorin has an attachment site for one chondroitin sulphate/dermatan sulphate side chain, whereas biglycan has two attachment sites for chondroitin sulphate/dermatan sulphate side chains [8]. Decorin was named as such because it is usually found in association with or decorating collagen fibrils [15]. Lumican, a keratin sulphate proteoglycan, is present diffusely in peripheral lung tissue, mainly in vessel walls $[16,17]$. The third family of extracellular matrix proteoglycans is the family of heparan sulphate proteoglycans, which includes perlecan, collagen XVIII and agrin. Perlecan is a large proteoglycan consisting of five domains, which contain low density lipoprotein receptor class A modules, immunoglobulin-like repeats, laminin-like repeats and epidermal growth factor-like repeats [18]. Electron micrographs of perlecan showed a protein with the appearance of beads on a string, which resulted in the name perlecan [8]. Whereas heparan sulphate is the predominant glycosaminoglycan on perlecan, chondroitin sulphate chains are found on domain V of recombinant perlecan [19]. Collagen XVIII is a heparan sulphate proteoglycan with features typical of collagen, including sensitivity of the core protein to collagenase [20]. This heparan sulphate proteoglycan is of particular interest because of the presence of endostatin, a $22 \mathrm{kDa}$ antiangiogenic peptide located in the C-terminal domain of collagen XVIII [21]. Agrin is a heparan sulphate proteoglycan found in the alveolar and capillary basement membrane, which contains nine follistatin-like domains which share similarity to Kazal-type protease inhibitors, including pancreatic trypsin inhibitor, follistatin, thrombin inhibitor and elastase inhibitor $[22,23]$.

\section{Glycosaminoglycans}

Glycosaminoglycans are linear polymers of repeating disaccharides with a high negative charge imparted by sulphate and/or carboxyl groups in their structure. There are four classes of glycosaminoglycans: 1) hyaluronan, 2) chondroitin sulphate/dermatan sulphate, 3) heparan sulphate/heparin, and 4) keratan sulphate. All four classes of glycosaminoglycan are found in normal lungs and all except hyaluronan are bound to core proteins [9]. The predominant glycosaminoglycan in normal lungs is heparan sulphate (40-60\%) followed by chondroitin sulphate/dermatan sulphate $(31 \%)$, hyaluronan $(14 \%)$ and heparin (5\%) [24]. Sulphation of glycosaminoglycans, a structural modification that occurs in the Golgi complex during chain elongation, has important biological consequences, as specific sulphation patterns on glycosaminoglycans form the binding sites for a number of proteins, including morphogens, growth factors, adhesion molecules, cytokines and chemokines [25-27].

\section{Distribution of matrix proteoglycans}

\section{Basement membrane}

The basement membrane or basal lamina of pulmonary epithelium contains proteoglycans that interact directly with epithelial cells and is divided into the lamina rara externa and the lamina densa, as seen in routinely prepared tissues by electron microscopy (fig. 1). Proteoglycans found in the basement membrane include the heparan sulphate proteoglycans, perlecan, agrin and collagen XVIII. Collagen IV is the only collagen which is more abundant in the basement membrane than collagen XVIII. Studies performed using high iron diamine (HID), a cationic probe that detects sulphated carbohydrates, indicate that there are microdomains of varying amounts of sulphation in the basement membranes of the lungs. For example, heparan sulphate in the basement membranes of alveolar type I and type II cells have differences in the amount of sulphation, with twice as much sulphation found in the lamina rara externa of type I cells as type II cells (fig. 2) [28]. A second example of these microdomains is shown by differences in sulphation of the basement membrane of pulmonary endothelial cells. The basement membrane underlying the endothelium of pulmonary capillaries has significantly less sulphation (fig. 2) when compared with the basement membrane underlying endothelial cells of postcapillary venules (fig. 3). The mechanisms that regulate the formation of these microdomains of high and low sulphation are not known.

\section{Interstitial space}

The large chondroitin sulphate proteoglycan, versican, is located in the interstitial spaces in the lungs where it interacts with hyaluronan, which fixes this proteoglycan in tissue as a very high molecular weight aggregate. Decorin and biglycan are also located in the interstitial spaces of the lungs where decorin binds collagen fibres with a regular periodicity. Staining of collagen fibrils with HID reaction products is most likely to be due to the binding of this cationic probe with the chondroitin sulphate side chains of decorin (fig. 3). 

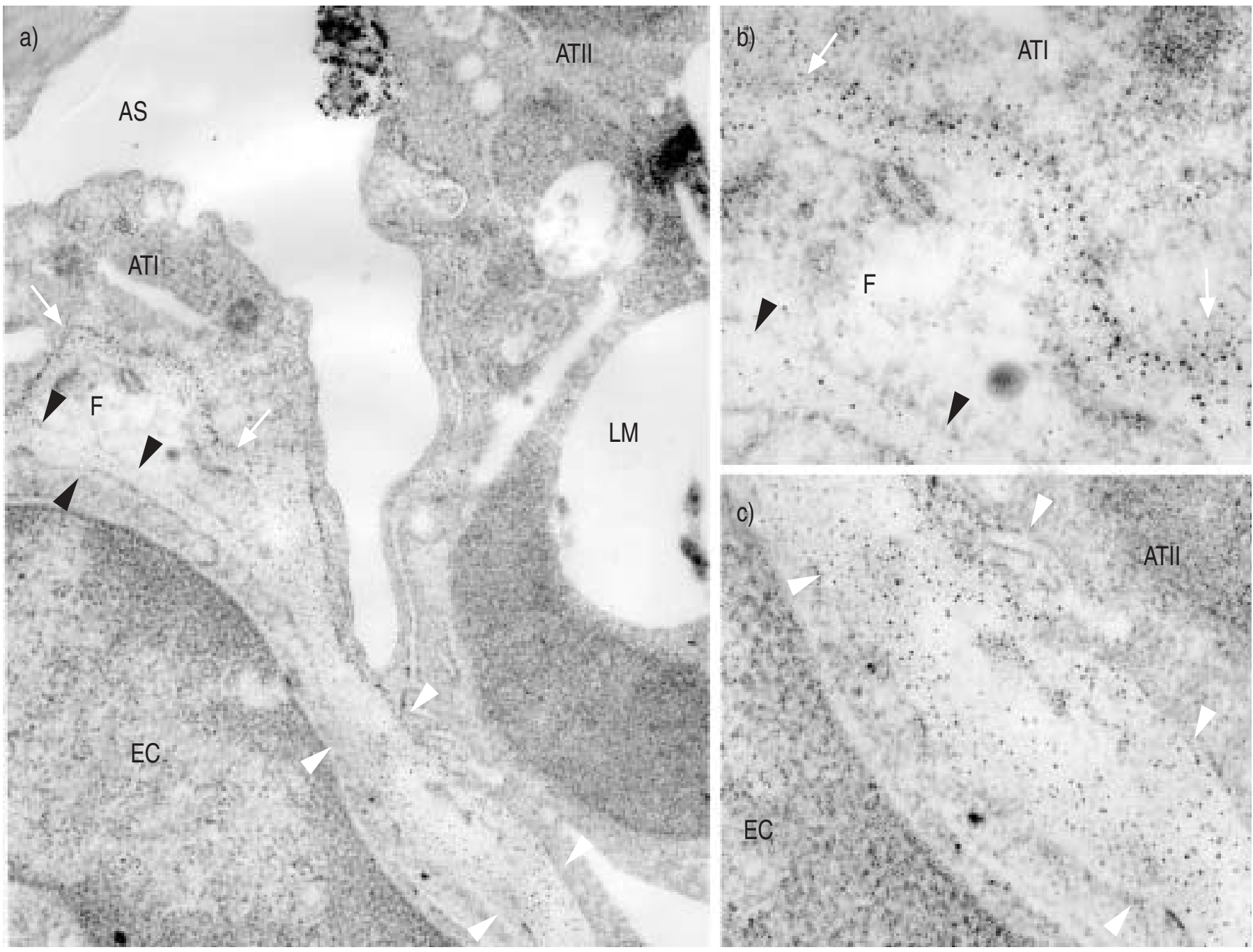

FIGURE 2. An electron micrograph of normal lung tissue showing microdomains in the extracellular matrix which contain varying amounts of sulphation. Cytochemical visualisation of sulphation in the extracellular matrix was performed using high iron diamine (HID), which binds to sulphates in lung tissue. The HID reaction product forms discrete 5-12 nm silver particles following appropriate intensification and is seen as discrete dark spots [29]. The basement membrane under a type I cell (ATI) and an adjacent fibroblast $(F)$ is highly sulphated (white arrows in a and $b$ ). The microdomains surrounding the pulmonary fibroblast show this cell to have microdomains of high and low sulphation. The extracellular matrix adjacent to the type I epithelial cell is highly sulphated (white arrows in a and b) whereas the extracellular matrix adjacent to the endothelial cell (EC) is undersulphated (black arrowheads in a and b). In contrast to the ATI cell, this electron micrograph shows that the extracellular matrix underlying the type II cell (ATII) is undersulphated. White arrowheads in a) and c) define the extracellular matrix underlying the ATIl cell and a pulmonary capillary EC. AS: alveolar space; LM: lamellar body.

\section{Basilar surface of cells}

Syndecans are a small family of transmembrane heparan sulphate proteoglycans that interact with a number of proteins in the extracellular matrix. Whereas syndecans are not considered extracellular matrix proteoglycans, and are therefore not discussed in detail here, their interaction with extracellular matrix transmits signals that are involved in focal adhesion and cell-death pathways [30]. Syndecan-1 and -4 have also been implicated in leukocyte migration [31-33].

\section{Biomechanical properties of proteoglycans}

Extracellular matrix proteoglycans confer important biomechanical properties to lung tissue. Glycosaminoglycans are strongly hydrophilic and their high negative charge attracts cations, such as $\mathrm{Na}^{+}$, which pulls water into the extracellular matrix through osmotic activity. The large amount of water pulled into the matrix by glycosaminoglycans results in swelling of the extracellular matrix, which allows it to withstand compressive forces and probably promotes movement of solutes and cells. Proteoglycans interact with other extracellular matrix molecules, such as collagen, laminin and elastin, to form a structured matrix and this interaction contributes to lung elasticity and alveolar stability [34, 35]. In the kidney, anionic sites in the glomerular basement membrane are composed primarily of heparan sulphate proteoglycans, which provide the main charge-selective barrier to plasma proteins $[36,37]$. The pulmonary microvascular barrier behaves as a net negative charge [38] and, although heparan sulphate is the most abundant of the negatively charged components in the alveolar basement membrane, it is 

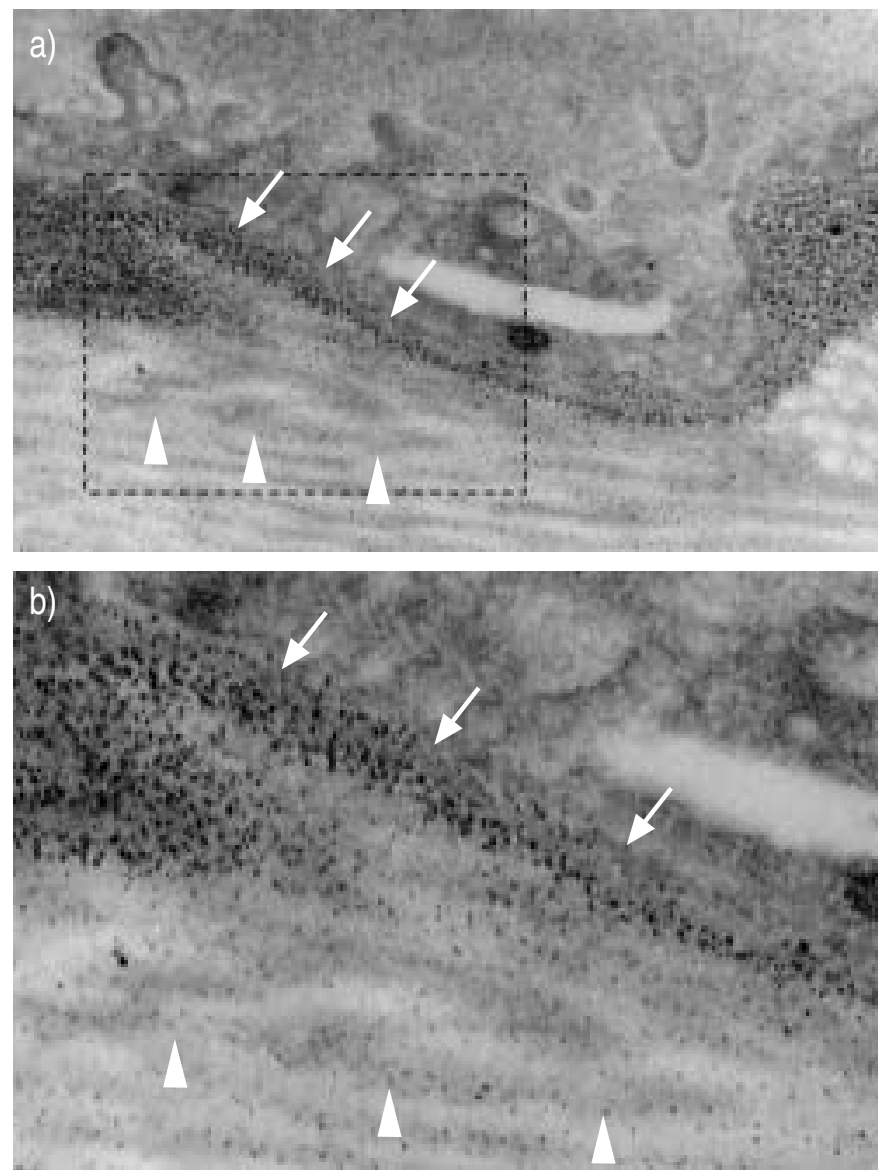

FIGURE 3. An electron micrograph of normal lung tissue showing a highly sulphated microdomain in the extracellular matrix underlying a postcapillary venule (a). An enlargement of the inset area enclosed by hatched lines is shown in (b). The extracellular matrix directly underlying the endothelial cell is highly sulphated (white arrows). The sulphation in the interstitial space has a regular periodicity (white arrow heads), which is consistent with decorin binding to collagen fibrils.

not known if it provides a charge-selective barrier to plasma proteins.

\section{Proteoglycans as determinants of epithelial cell phenotype}

Proteoglycans are important determinants of cellular phenotype, playing a role in development, cellular proliferation, cell death, inflammation and wound healing. A critical function of proteoglycans in the extracellular matrix is mediated by glycosaminoglycan side chains, which bind to growth factors, cytokines and chemokines [25-27, 39-42]. The binding of these proteins to glycosaminoglycans was initially believed to be a nonspecific ionic interaction between positively charged amino acids on proteins and negatively charged sulphates on glycosaminoglycans. It is now known that considerable specificity exists in the interaction between proteins and glycosaminoglycans, with unique binding sites being identified on glycosaminoglycans for proteins such as thrombin and growth factors [27, 43]. Despite a wealth of knowledge from studies showing a role for extracellular proteoglycans in regulating cellular function in vitro, very little is known about their role in regulating epithelial cell function in the lungs.
Five potential functions of protein-glycosaminoglycan interactions in regulating epithelial cell phenotype in the lungs are listed below.

\section{Determination of protein binding sites}

Because of the specificity observed in proteinglycosaminoglycan interactions, extracellular matrix proteoglycans localise proteins such as chemokines and fibroblast growth factors (FGFs) to distinct anatomical sites, e.g. basement membrane or intersitial spaces $[25,26]$. FGF-2 and -4 provide excellent examples of this specificity because these two growth factors bind to different anatomical locations in the lungs, and this difference in binding is mediated by heparan sulphate. Whereas FGF-2 binds to heparan sulphate in lung tissue and on endothelial cells, FGF-4 binding in lungs is restricted, binding to heparan sulphate in lung tissue but not on endothelial cells. This suggests that FGF-4 and -2 bind to distinct sulphation patterns, and that the sulphation pattern required for FGF-4 binding is not expressed in most vascular tissues [25].

\section{Storage/sequestration}

Glycosaminoglycans provide a site to which proteins can bind; this sequesters a protein and prolongs its retention in lung tissue. The binding of chemokines to glycosaminoglycans provides a site for dimerisation of chemokines, which is a mechanism shown to increase the amount of chemokine binding in the lungs [26, 44]. Undersulphation of the lamina rara externa of basement membrane microdomains adjacent to alveolar type II cells compared with that of neighbouring type I cells is a mechanism that may account for some of the known morphological and functional differences between these alveolar epithelial cells (fig. 2) [28, 39, 40]. Increased sulphation of glycosaminoglycans under type I cells sequesters growth factors (i.e. FGF-2), limiting their effect on this cell. Injury or damage to these highly sulphated sites in the extracellular matrix results in the proteolytic liberation of FGF-2. In the undersulphated microenvironment in the extracellular matrix beneath type II cells, FGF-2 has access to specific cell surface receptors, thus promoting activation signalling pathways in this cell.

\section{Formation and stabilisation of morphogen and chemokine gradients}

The binding of morphogens and chemokines to glycosaminoglycans has been proposed as a mechanism whereby gradients develop in tissue. The binding affinity of morphogens and chemokines to glycosaminoglycans, which is in the low micromolar range, provides a mechanism whereby these molecules are able to diffuse and form gradients in tissue. This specific interaction is determined by the glycosaminoglycanbinding site on the protein and specific sulphation patterns found on glycosaminoglycans in tissue [28, 41, 45-49].

\section{Cell signalling}

The binding of growth factors and cytokines to glycosaminoglycans has been shown to play an important role in the activation of their receptors on the cell surface [50]. In contrast, the sequestration of FGFs by heparan sulphate in the basement membrane prevents the interaction with their receptors on epithelial cells [40]. Therefore, the ability of growth factors to 
activate epithelial cells will depend on the location where the growth factor binds to heparan sulphate. Growth factors sequestered by heparan sulphate in the extracellular matrix will have limited effects on epithelial cell function, whereas ligands that bind to heparan sulphate on the cell surface will activate growth factor receptors and alter epithelial cell function.

\section{Protection from proteolysis}

The binding of a protein to a glycosaminoglycan may conceal proteolytic cleavage sites, which protects the protein from proteolysis. Glycosaminoglycans have been shown to protect chemokines and growth factors from proteolysis [51, 52].

\section{MATRIX PROTEOGLYCANS AND LUNG DISEASE Alterations in the composition of glycosaminoglycans} Changes in the composition of glycosaminoglycans and proteoglycans in the lungs have been reported in animal models and human lung disease. A consistent finding in animal models, such as exposure to lipopolysaccharide and bleomycin, is an increase in the synthesis of chondroitin sulphate and dermatan sulphate [53-55]. Gram-negative bacterial pneumonia results in the increased expression of chondroitin sulphate in the lungs of rabbits within $24 \mathrm{~h}$ (fig. 4). Hyaluronan is increased in a number of lung diseases, including acute respiratory distress syndrome, fibrosis, ventilator-induced lung injury and chronic obstructive pulmonary disease [56-60].

\section{Changes in core protein expression}

An increased deposition of the chondroitin sulphate proteoglycans versican, decorin and biglycan is associated with a number of lung diseases. Versican is increased in patients with asthma, acute respiratory distress syndrome, idiopathic pulmonary fibrosis, bronchiolitis obliterans organising pneumonia and lymphangioleiomyomatosis [61-64]. Often associated with the increased expression of versican in the lungs is an increased deposition of hyaluronan, which would result in the formation of large molecular weight complexes of hyaluronan and versican.

\section{Matrix proteoglycans and epithelial cell phenotype in diseased lungs}

Changes in the composition of extracellular matrix proteoglycans and glycosaminoglycans are likely to affect the clinical course of lung diseases. However, very little is known about the effect of altered extracellular matrix on epithelial cell function. Patients with severe asthma have increased expression of versican and biglycan in their airways, which is correlated with increased airway responsiveness [65]. Decorin decreases the fibrotic response of bleomycin in the lungs, possibly by inhibition of TGF- $\beta$ bioactivity, suggesting that this chondroitin sulphate proteoglycan has anti-inflammatory properties [66, 67]. The biological effects of versican can be somewhat varied if not contradictory, because versican can both increase and decrease specific cellular functions. This is better understood in the context of the different isoforms of versican, the modular structure of the versican core protein and the binding partners for versican [68]. For example, the V1 isoform of versican increased the proliferation of 3T3 fibroblasts and protected these cells from apoptosis. In contrast, the

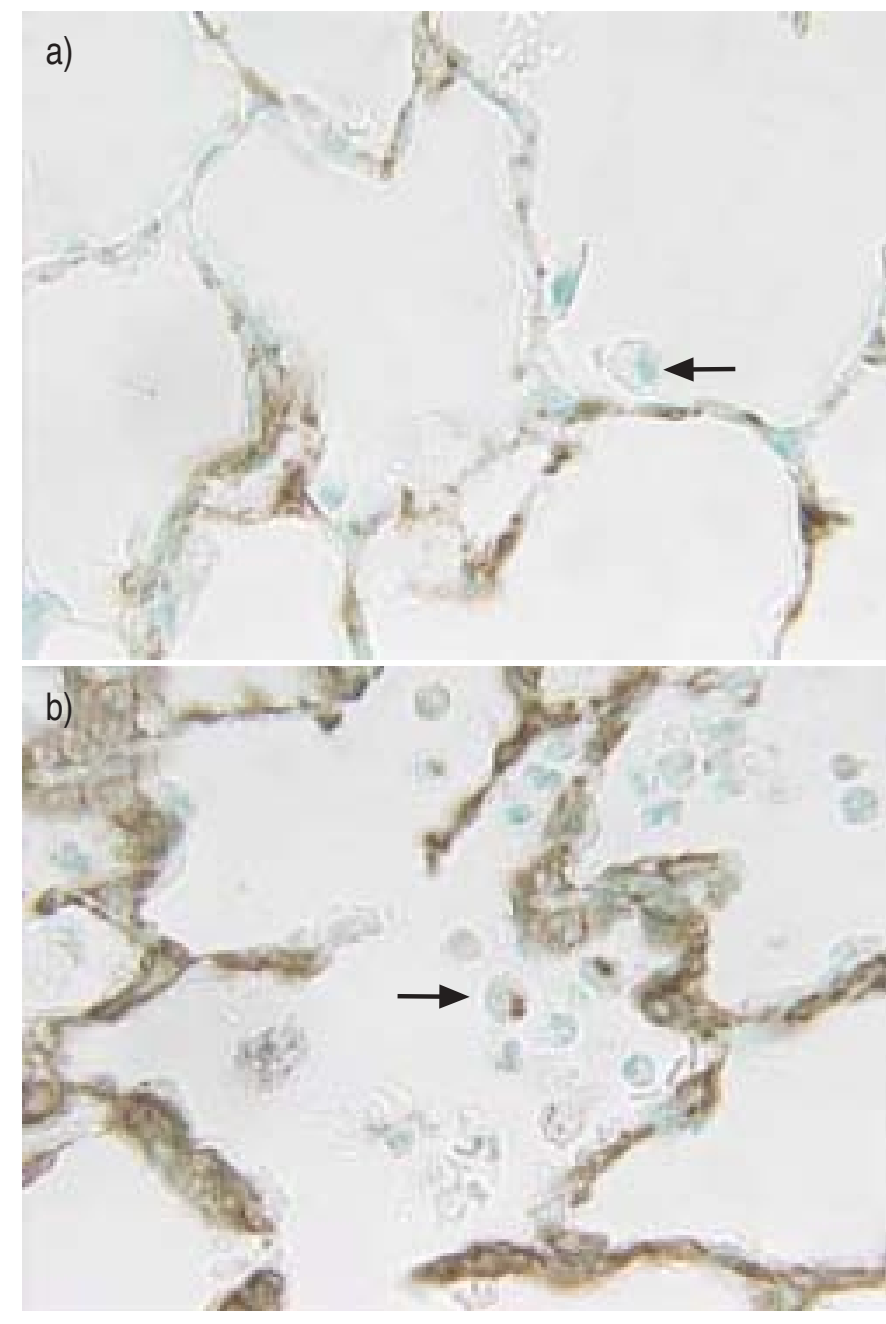

FIGURE 4. Increased expression of chondroitin sulphate proteoglycan in the lungs of a rabbit with Escherichia coli pneumonia. Immunohistochemistry performed using the mouse monoclonal antibody CS-56 (Sigma; St. Louis, MO, USA), which recognises chondroitin sulphate glycosaminoglycans, shows chondroitin sulphate (brown) in a) normal and b) inflamed rabbit lungs. In normal lungs, there is a multifocal distribution of chondroitin sulphate in the alveolar septa and no chondroitin sulphate in alveolar macrophages (a; arrow). In contrast, in inflamed lungs, chondroitin sulphate is increased in the alveolar septa and is found in alveolar macrophages (b; arrow).

V2 isoform of versican exhibited the opposite effect by inhibiting 3T3 cell proliferation and by not protecting against apoptosis [69]. Future studies will need to determine whether changes in the extracellular matrix proteoglycans during lung disease affect epithelial cell function in the lungs.

\section{Activation of Toll-like pathways by degradation of the extracellular matrix}

Mounting evidence suggests that Toll-like receptors not only recognise pathogen-associated molecular patterns but also endogenous factors, such as degradation products of fibronectin, heparan sulphate, hyaluronan and biglycan [70-74]. This has lead to the hypothesis that matrix degradation acts as an endogenous biological "danger" signal. Pulmonary epithelial cells express Toll-like receptors and therefore may be activated upon recognition of matrix degradation products [75]. 


\section{CONCLUSIONS}

Extracellular matrix proteoglycans and glycosaminoglycans play an important role in the regulation of lung function in both normal and diseased lungs. New information about these diverse molecules has resulted in a shift in the paradigm whereby extracellular matrix proteoglycans modify lung function in health and disease. Initially, extracellular matrix proteoglycans were considered to be the molecular glue that provides structural support and maintains the extracellular microarchitecture. Whereas these are important functions of extracellular matrix proteoglycans, it has turned out that these diverse molecules regulate a variety of key biological processes, such as development, immune system function and tissue homeostasis, and pathological processes, such as inflammation, cardiovascular disease and cancer. This suggests that extracellular matrix proteoglycans play a critical role in regulating epithelial cell function in the lungs.

\section{REFERENCES}

1 Wright JR, Dobbs LG. Regulation of pulmonary surfactant secretion and clearance. Annu Rev Physiol 1991; 53: 395-414.

2 Diamond G, Legarda D, Ryan LK. The innate immune response of the respiratory epithelium. Immunol Rev 2000; 173: $27-38$

3 Diamond G, Kaiser V, Rhodes J, Russell JP, L. Bevins C. Transcriptional regulation of beta-defensin gene expression in tracheal epithelial cells. Infect Immunol 2000; 68: 113-119.

4 Skerrett SJ, Liggitt HD, Hajjar AM, Ernst RK, Miller SI, Wilson CB. Respiratory epithelial cells regulate lung inflammation in response to inhaled endotoxin. $A m J$ Physiol Lung Cell Mol Physiol 2004; 287: L143-L152.

5 Wright JR. Immunoregulatory functions of surfactant proteins. Nat Rev Immunol 2005; 5: 58-68.

6 Matthay MA, Clerici C, Saumon G. Invited review: active fluid clearance from the distal air spaces of the lung. J Appl Physiol 2002; 93: 1533-1541.

7 Zemans RL, Matthay MA. Bench-to-bedside review: the role of the alveolar epithelium in the resolution of pulmonary edema in acute lung injury. Crit Care 2004; 8: 469-477.

8 Wight TN, Heinegard DK, Hascall VC. Proteoglycans: Structure and Function. In: Hay E, ed. Cell Biology of the Extracellular Matrix, 2nd Edn. New York, NY, Plenum Press, 1991: pp. 45-77.

9 Roberts CR, Wight TN, Hascall VC. Proteoglycans. In: Crystal R, West J, Weibel E and Barnes P, eds. The Lung: Scientific Foundations. 2nd Edn. Philadelphia, PA, Lippincott-Raven Press, 1997: pp. 757-767.

10 Bosman FT, Stamenkovic I. Functional structure and composition of the extracellular matrix. J Pathol 2003; 200: 423-428.

11 Kinsella MG, Bressler SL, Wight TN. The regulated synthesis of versican, decorin, and biglycan: extracellular matrix proteoglycans that influence cellular phenotype. Crit Rev Eukaryot Gene Expr 2004; 14: 203-234.

12 Cattaruzza S, Schiappacassi M, Ljungberg-Rose A, et al. Distribution of PG-M/versican variants in human tissues and de novo expression of isoform V3 upon endothelial cell activation, migration, and neoangiogenesis in vitro. $J$ Biol Chem 2002; 277: 47626-47635.

13 Kolb M, Margetts PJ, Sime PJ, Gauldie J. Proteoglycans decorin and biglycan differentially modulate TGF-betamediated fibrotic responses in the lung. Am J Physiol Lung Cell Mol Physiol 2001; 280: L1327-L1334.

14 Nadesalingam J, Bernal AL, Dodds AW, et al. Identification and characterization of a novel interaction between pulmonary surfactant protein D and decorin. J Biol Chem 2003; 278: 25678-25687.

15 Krusius T, Ruoslahti E. Primary structure of an extracellular matrix proteoglycan core protein deduced from cloned cDNA. Proc Natl Acad Sci USA 1986; 83: 7683-7687.

16 Ying S, Shiraishi A, Kao CW, et al. Characterization and expression of the mouse lumian gene. J Biol Chem 1997; 272: 30306-30313.

17 Dolhnikoff M, Morin J, Roughley PJ, Ludwig MS. Expression of lumican in human lungs. Am J Respir Cell Mol Biol 1998; 19: 582-587.

18 Noonan DM, Fulle A, Valente $\mathrm{P}$, et al. The complete sequence of perlecan, a basement membrane heparan sulphate proteoglycan, reveals extensive similarity with laminin A chain, low density lipoprotein-receptor, and the neural cell adhesion molecule. J Biol Chem 1991; 266: 22939-22947.

19 Tapanadechopone P, Hassell JR, Rigatti B, Couchman JR. Localization of glycosaminoglycan substitution sites on domain V of mouse perlecan. Biochem Biophys Res Common 1999; 265: 680-690.

20 Halfter W, Dong S, Schurer B, Cole GJ. Collagen XVIII is a basement membrane heparan sulfate proteoglycan. J Biol Chem 1998; 273: 25404-25412.

21 Sasaki T, Fukai N, Mann K, Gohring W, Olsen BR, Timpl R. Structure, function and tissue forms of the C-terminal globular domain of collagen XVIII containing the angiogenesis inhibitor endostatin. EMBO J 1998; 17: 4249-4256.

22 Groffen AJ, Buskens CA, van Kuppevelt TH, Veerkamp JH, Monnens LA, van den Heuvel LP. Primary structure and high expression of human agrin in basement membranes of adult lung and kidney. Eur J Biochem 1998; 254: 123-128.

23 Erickson AC, Couchman JR. Still more complexity in mammalian basement membranes. J Histochem Cytochem 2000; 48: 1291-1306.

24 Sampson PM, Boyd RB, Pietra GG, Fishman AP. Glycosaminoglycan biosynthesis in the isolated perfused rat lung. J Appl Physiol 1984; 57: 1648-1654.

25 Allen BL, Filla MS, Rapraeger AC. Role of heparan sulfate as a tissue-specific regulator of FGF-4 and FGF receptor recognition. J Cell Biol 2001; 155: 845-858.

26 Frevert CW, Kinsella MG, Vathanaprida C, et al. Binding of interleukin-8 to heparan sulfate and chondroitin sulfate in lung tissue. Am J Respir Cell Mol Biol 2003; 28: 464-472.

27 Esko JD, Selleck SB. Order out of chaos: assembly of ligand binding sites in heparan sulfate. Annu Rev Biochem 2002; 71: 435-471.

28 Sannes PL. Differences in basement membrane-associated microdomains of type I and type II pneumocytes in the rat and rabbit lung. J Histochem Cytochem 1984; 32: 827-833. 
29 Sannes PL, Spicer SS, Katsuyama T. Ultrastructural localization of sulphated complex carbohydrates with a modified iron diamine procedure. J Histochem Cytochem 1979; 27: 1108-1111.

30 Jeong J, Han I, Lim Y, et al. Rat embryo fibroblasts require both the cell-binding and the heparin-binding domains of fibronectin for survival. Biochem J 2001; 356: 531-537.

31 Li Q, Park PW, Wilson CL, Parks WC. Matrilysin shedding of syndecan-1 regulates chemokine mobilization and transepithelial efflux of neutrophils in acute lung injury. Cell 2002; 111: 635-646.

32 Feistritzer C, Kaneider NC, Sturn DH, Wiedermann CJ. Syndecan-4-dependent migration of human eosinophils. Clin Exp Allergy 2004; 34: 696-703.

33 Gotte M. Syndecans in inflammation. FASEB J 2003; 17: 575-591.

34 Fust A, LeBellego F, Iozzo RV, Roughley PJ, Ludwig MS. Alterations in lung mechanics in decorin-deficient mice. Am J Physiol Lung Cell Mol Physiol 2005; 288: L159-L166.

35 Cavalcante FS, Ito S, Brewer K, et al. Mechanical interactions between collagen and proteoglycans: implications for the stability of lung tissue. J Appl Physiol 2005; 98: 672-679.

36 Caulfield JP, Farquhar MG. The permeability of glomerular capillaries to graded dextrans. Identification of the basement membrane as the primary filtration barrier. J Cell Biol 1974; 63: 883-903.

37 Kanwar YS, Veis A, Kimura JH, Jakubowski ML. Characterization of heparin sulfate-proteoglycan of glomerular basement membranes. Proc Natl Acad Sci USA 1984; 81: 762-766.

38 Sanders JR, Pou NA, Roselli RJ. Neutral and DEAE dextrans as tracers for assessing lung microvascular barrier permeability and integrity. J Appl Physiol 2002; 93: 251-262.

39 Sannes PL, Khosla J, Peters BP. Biosynthesis of sulfated extracellular matrices by alveolar type II cells increases with time in culture. Am J Physiol 1997; 273: L840-L847.

40 Sannes PL, Khosla J, Li CM, Pagan I. Sulfation of extracellular matrices modifies growth factor effects on type II cells on laminin substrata. Am J Physiol 1998; 275: L701-L708.

41 Smits NC, Robbesom AA, Versteeg EM, Van De Westerlo EM, Dekhuijzen PN, Van Kuppevelt TH. Heterogeneity of heparan sulfates in human lung. Am J Respir Cell Mol Biol 2004; 30: 166-173.

42 Gallagher JT. Heparan sulfate: growth control with a restricted sequence menu. J Clin Invest 2001; 108: 357-361.

43 Capila I, Linhardt RJ. Heparin-protein interactions. Angew Chem Int Ed Engl 2002; 41: 391-412.

44 Frevert CW, Goodman RB, Kinsella MG, et al. Tissuespecific mechanisms control the retention of IL-8 in lungs and skin. J Immunol 2002; 168: 3550-3556.

45 Kuschert GS, Hoogewerf AJ, Proudfoot AE, et al. Identification of a glycosaminoglycan binding surface on human interleukin-8. Biochemistry 1998; 37: 11193-11201.

46 Spillmann D, Witt D, Lindahl U. Defining the interleukin8-binding domain of heparan sulfate. J Biol Chem 1998; 273: 15487-15493.

47 Kuschert GS, Coulin F, Power CA, et al. Glycosaminoglycans interact selectively with chemokines and modulate receptor binding and cellular responses. Biochemistry 1999; 38: 12959-12968.

48 Lortat-Jacob H, Grosdidier A, Imberty A. Structural diversity of heparan sulphate binding domains in chemokines. PNAS 2002; 99: 1229-1234.

49 Knox S, Merry C, Stringer S, Melrose J, Whitelock J. Not all perlecans are created equal: interactions with fibroblast growth factor (FGF) 2 and FGF receptors. J Biol Chem 2002; 277: 14657-14665.

50 Mohammadi M, Olsen SK, Ibrahimi OA. Structural basis for fibroblast growth factor receptor activation. Cytokine Growth Factor Rev 2005; 16: 107-137.

51 Gospodarowicz D, Cheng J. Heparin protects basic and acidic FGF from inactivation. J Cell Physiol 1986; 128: 475-484.

52 Sadir R, Imberty A, Baleux F, Lortat-Jacob H. Heparan sulfate/heparin oligosaccharides protect stromal cellderived factor-1 (SDF-1)/CXCL12 against proteolysis induced by CD26/dipeptidyl peptidase IV. J Biol Chem 2004; 279: 43854-43860.

53 Blackwood RA, Cantor JO, Moret J, Mandl I, Turino GM. Glycosaminoglycan synthesis in endotoxin-induced lung injury. Proc Soc Exp Biol Med 1983; 174: 343-349.

54 Karlinsky JB, Bucay PJ, Ciccolella DE, Crowley MP. Effects of intratracheal endotoxin administration on hamster lung glycosaminoglycans. Am J Physiol 1991; 261: L148-L155.

55 Westergren-Thorsson G, Hernnas J, Sarnstrand B, Oldberg A, Heinegard D, Malmstrom A. Altered expression of small proteoglycans, collagen, and transforming growth factor-B1 in developing bleomycin-induced pulmonary fibrosis in rats. J Clin Invest 1993; 92: 632-637.

56 Hallgren R, Samuelsson T, Laurent TC, Modig J. Accumulation of hyaluronan (hyaluronic acid) in the lung in adult respiratory distress syndrome. Am Rev Respir Dis 1989; 139: 682-687.

57 Westergren-Thorsson G, Sime P, Jordana M, Gauldie J, Sarnstrand B, Malmstrom A. Lung fibroblast clones from normal and fibrotic subjects differ in hyaluronan and decorin production and rate of proliferation. Int J Biochem Cell Biol 2004; 36: 1573-1584.

58 Wilkinson TS, Potter-Perigo S, Tsoi C, Altman LC, Wight TN. Pro- and anti-inflammatory factors cooperate to control hyaluronan synthesis in lung fibroblasts. Am J Respir Cell Mol Biol 2004; 31: 92-99.

59 Bai KJ, Spicer AP, Mascarenhas MM, et al. The role of hyaluronan synthase 3 in ventilator-induced lung injury. Am J Respir Crit Care Med 2005; 172: 92-98.

60 Dentener MA, Vernooy JH, Hendriks S, Wouters EF. Enhanced levels of hyaluronan in lungs of patients with COPD: relationship with lung function and local inflammation. Thorax 2005; 60: 114-119.

61 de Medeiros Matsushita M, da Silva LF, Dos Santos MA, et al. Airway proteoglycans are differentially altered in fatal asthma. J Pathol 2005; 207: 102-110.

62 Bensadoun ES, Burke AK, Hogg JC, Roberts CR. Proteoglycan deposition in pulmonary fibrosis. $A m I$ Respir Crit Care Med 1996; 154: 1819-1828.

63 Bensadoun ES, Burke AK, Hogg JC, Roberts CR. Proteoglycans in granulomatous lung diseases. Eur Respir J 1997; 10: 2731-2737. 
64 Merrilees MJ, Hankin EJ, Black JL, Beaumont B. Matrix proteoglycans and remodelling of interstitial lung tissue in lymphangioleiomyomatosis. J Pathol 2004; 203: 653-660.

65 Westergren-Thorsson G, Chakir J, Lafreniere-Allard MJ, Boulet LP, Tremblay GM. Correlation between airway responsiveness and proteoglycan production by bronchial fibroblasts from normal and asthmatic subjects. Int $J$ Biochem Cell Biol 2002; 34: 1256-1267.

66 Giri SN, Hyde DM, Braun RK, Gaarde W, Harper JR, Pierschbacher MD. Antifibrotic effect of decorin in a bleomycin hamster model of lung fibrosis. Biochem Pharmacol 1997; 54: 1205-1216.

67 Kolb M, Margetts PJ, Galt T, et al. Transient transgene expression of decorin in the lung reduces the fibrotic response to bleomycin. Am J Respir Crit Care Med 2001; 163: 770-777.

$68 \mathrm{Wu}$ YJ, Lapierre D, Wu J, Yee AJ, Yang BB. The interaction of versican with its binding partners. Cell Res 2005; 15 : 483-494.

69 Sheng W, Wang G, Wang Y, et al. The roles of versican v1 and v2 isoforms in cell proliferation and apoptosis. Mol Biol Cell 2005; 16: 1330-1340.
70 Okamura Y, Watari M, Jerud ES, et al. The extra domain A of fibronectin activates Toll-like receptor 4. J Biol Chem 2001; 276: 10229-10233.

71 Johnson GB, Brunn GJ, Kodaira Y, Platt JL. Receptormediated monitoring of tissue well-being via detection of soluble heparan sulfate by Toll-like receptor 4 . J Immunol 2002; 168: 5233-5239.

72 Termeer C, Benedix F, Sleeman J, et al. Oligosaccharides of hyaluronan activate dendritic cells via Toll-like receptor 4 . J Exp Med 2002; 195: 99-111.

73 Johnson GB, Brunn GJ, Platt JL. Cutting edge: an endogenous pathway to systemic inflammatory response syndrome (SIRS)-like reactions through Toll-like receptor 4. J Immunol 2004; 172: 20-24.

74 Schaefer L, Babelova A, Kiss E, et al. The matrix component biglycan is proinflammatory and signals through Toll-like receptors 4 and 2 in macrophages. J Clin Invest 2005; 115: 2223-2233.

75 Kajikawa O, Frevert CW, Lin SM, et al. Gene expression of Toll-like receptor-2, Toll-like receptor-4, and MD2 is differentially regulated in rabbits with Escherichia coli pneumonia. Gene 2005; 344: 193-202. 